\title{
Controlling the Yawing of an Aframax Tanker During a Lightering Manoeuvre
}

\author{
E. Lataire*, G. Delefortrie**, M. Vantorre*** \\ * Ghent University, Maritime Technology Division, Technologiepark 904, 9052 Ghent, Belgium \\ (Tel: 0032-9 26455 57; e-mail:Evert.Lataire@UGent.be). \\ ** Flanders Hydraulics Research, Berchemlei 115, 2140 Antwerp, Belgium, \\ (e-mail: Guillaume.Delefortrie@mow.vlaanderen.be) \\ *** Ghent University, Maritime Technology Division, Technologiepark 904, 9052 Ghent, Belgium \\ (e-mail: Marc.Vantorre@UGent.be).
}

\begin{abstract}
Lightering is the process where a larger ship (the ship to be lightered, STBL) transfers (parts of) its cargo to a smaller vessel, known as service ship. This transfer occurs at a slow sailing speed (about 4 knots) while both ships are moored to each other. A knowledge-building project with user involvement entitled "Investigating Hydrodynamic Aspects and Control Strategies for Ship-to-Ship Operations" was carried out in 2007-2011 to offer more insight in lightering operations. The actual forces acting on both vessels while preparing for lightering can be analysed based upon more than two thousand captive model tests carried out at the Towing tank for manoeuvres in shallow water (co-operation Flanders Hydraulics Research - Ghent University) in Antwerp, Belgium. The tests were executed with a scale model of a very large crude oil carrier (VLCC) attached to the main frame of the towing carriage and a scale model of an Aframax tanker attached to the computer controlled planar motion carriage. Forces, moments and vertical positions were measured on both models.

In this article particular attention is given to the comparison, in deep and shallow water, of the yawing moment induced on the service ship during the lightering operation and the yawing moment induced by the rudder of the same ship during open water tests. The combination of both allows defining ranges of relative positions between both vessels with an equal degree of controllability of the service ship during the lightering operation. In shallow water, the acceptable meeting area appears to be reduced significantly.
\end{abstract}

Keywords: Lightering, ship to ship interaction, yawing moment, control strategies.

\section{INTRODUCTION}

\subsection{Reasons for lightering}

During the past decades, driven by economical advantages the size of ships has known a continuous growth. Nevertheless several factors put limitations on the increasing ship size among which environmental issues are of particular attention when looking at oil transportation.

To take the oil to harbours located in environmentally sensitive areas a smaller ship size is preferred to decrease the hazards. Also a smaller ship will have a larger manoeuvrability in a shallow water area due to its advantageous larger under keel clearance. In order not to lose the scale advantages oil is transported over the oceans aboard of fully loaded ultra and very large crude oil carriers (ULCC, VLCC). If part of the oil needs to be discharged to a harbour located in a protected area, the discharge can occur at sea to a smaller vessel, further referred to as service ship, that can easily sail towards the harbour. The time losses of such operation are kept under control if the discharge or lightering manoeuvre is done while both ships are sailing at low speed.

\subsection{Common lightering operation}

The service ship initiates the lightering manoeuvre when sailing abreast of the ship to be lightered (STBL) with approximately the same heading and forward speed at a lateral distance of about $200 \mathrm{~m}$ from the STBL. Slowly the service ship approaches the STBL with a very small relative heading until both ships are at more or less the same longitudinal position. The vessels are then moored to each other with fenders of about $4 \mathrm{~m}$ diameter positioned in between both hulls and the manifolds for the oil transfer are deployed so that the actual cargo transfer can begin.

When the transfer is completed, the service ship is detached and in the final phase of the lightering manoeuvre the forward speed increases slightly. Throughout the lightering manoeuvre, the (much larger) STBL keeps its course and speed constant.

\section{EXPERIMENTAL PROGRAM}

\subsection{Test Facilities}

The towing tank for manoeuvres in shallow water with main dimensions $88 \times 7 \times 0.5 \mathrm{~m}^{3}$, is equipped with a planar motion carriage (consisting of a longitudinal or main carriage, a 
lateral carriage and a yaw table), a wave generator and an auxiliary carriage for ship-to-ship interaction tests with two ship models sailing at different speeds (overtaking and meeting manoeuvres). Full computer control allows unmanned operation of the facilities so that experimental programs can run day and night, seven days a week (Van Kerkhove et al., 2009). The number of test runs is only limited by the time needed for the water to calm down in between runs. A yearly average of 25 tests a day is achieved.

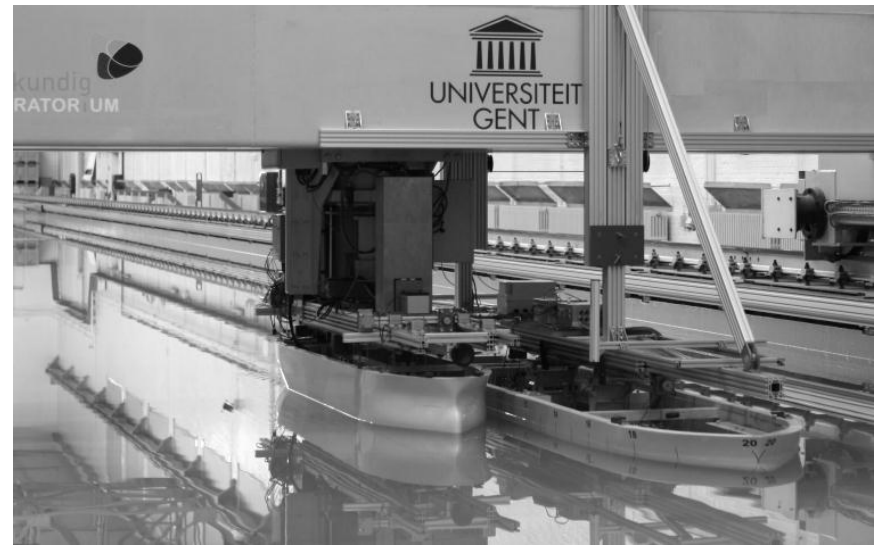

Fig. 1. Both ship models attached to the main carriage of the towing tank.

The auxiliary carriage for ship-to-ship interaction tests could not be used to carry out the lightering tests. Instead both ship models were attached to the main carriage as longitudinal speed differences were not desired (Figure 1). The service ship was attached to the horizontal planar motion mechanism (HPMM); while the STBL was attached to a purposely built Rose-Krieger frame, which only enabled a horizontal longitudinal position adjustment of the ship. Both ships were free to heave and pitch and restricted in the other degrees of freedom.

\subsection{Model Tests}

\subsubsection{Ship models}

The STBL is a $1 / 75$ scale model of a VLCC. The geometric properties of bare hull, propeller and rudder of this vessel are made available and published via SIMMAN (2008). This specific model is known as the KVLCC2 Moeri tanker and often used as a benchmark vessel by towing tanks worldwide (Stern and Agdrup, 2008). The service ship is a 1/75 scale model of an Aframax type of vessel of about 100000 DWT. The models have been tested with attached rudder and propeller.

The service ship has been tested in ballast condition and fully loaded, corresponding to the conditions before and after lightering (Lataire et al, 2009). The STBL was either fully loaded (before lightering) or at even keel with a displacement corresponding with the condition after the second off load (after lightering). In this article only the combination of a fully loaded service ship and the STBL after the second off load will be discussed (Table 1).
Table 1 Main properties of both ship models at model scale and full scale

\begin{tabular}{|c|c:c|c:c|c|}
\cline { 2 - 6 } \multicolumn{1}{c|}{} & \multicolumn{2}{c|}{ Service ship } & \multicolumn{2}{c|}{ STBL } & \multicolumn{1}{c|}{} \\
\hline Scale & 1 & 75 & 1 & 75 & {[]} \\
\hline $\mathrm{L}_{\mathrm{PP}}$ & 231.4 & 3.085 & 320.0 & 4.267 & {$[\mathrm{~m}]$} \\
\hline $\mathrm{B}$ & 42.0 & 0.560 & 58.0 & 0.773 & {$[\mathrm{~m}]$} \\
\hline & \multicolumn{2}{c|}{ Design condition } & 2 nd off load & \\
\hline $\mathrm{T}_{\mathrm{F}}$ & 15.0 & 0.200 & 12.8 & 0.171 & {$[\mathrm{~m}]$} \\
\hline $\mathrm{T}_{\mathrm{A}}$ & 15.0 & 0.200 & 12.8 & 0.171 & {$[\mathrm{~m}]$} \\
\hline$\nabla$ & 109139 & 0.259 & 182941 & 0.434 & {$\left[\mathrm{~m}^{3}\right]$} \\
\hline
\end{tabular}

The lightering manoeuvres were tested at two different water depths, namely at the maximal possible water depth in the towing tank and at an under keel clearance of $35 \%$ of the largest draft, which is here the draft of the service ship. Lightering manoeuvres presently occur in deep water conditions, anyhow the tests show that the already difficult lightering manoeuvre challenges the mooring masters' nerves to an extreme level in shallow water.

\subsubsection{Test types}

1981 steady state and 162 dynamic tests were carried out during the systematic research program. During a steady state test all kinematic and control parameters of both ships are kept constant.

The dynamic tests can be divided into three types. A first type of dynamic test consists of harmonically varying the rudder angle of the service ship as a function of time (from 40 degrees port to 40 degrees starboard and back) while the forward speed remains constant and the service ship does not yaw nor sway. In a second and third type of test the trajectory of the service ship harmonically changes either by imposing a harmonic yawing motion or a harmonic sway motion.

\subsubsection{Velocities}

The forward speed of both vessels during the captive model tests was either $2.0,4.0$ or 6.0 knots full scale. The runs were conducted at self-propulsion, meaning the propeller rate of the STBL and service ship always corresponded to the selfpropulsion point in open water i.e. without the influence of the service ship or STBL.

\subsubsection{Relative positions}

The tests have been carried out at different relative longitudinal ( $\mathrm{x}_{\mathrm{cc}}$ - distance between midship sections of both vessels) and lateral ( $\mathrm{y}_{\mathrm{bb}}-$ smallest distance between ship's sides) positions. The position $\mathrm{x}_{\mathrm{cc}}$ is positive when the service ship sails ahead of the STBL. The lateral position can also be expressed as $\mathrm{y}_{\mathrm{cb}}$, which is the distance between the centreline of the own ship and the side of the target ship. The relationship between $\mathrm{y}_{\mathrm{cb}}$ and $\mathrm{y}_{\mathrm{bb}}$ can be written as:

$y_{c b}=y_{b b}+\frac{B}{2}$

in which B represents the beam of the own ship. 
The range of tested lateral and longitudinal positions of the service ship with respect to the STBL was selected taking account of the common practice of lightering manoeuvres. Five lateral distances between both vessels' sides have been tested systematically during steady state and dynamic rudder tests, i.e. $\mathrm{y}_{\mathrm{bb}}=4.0,10.0,25.0,50.0$ and $100.0 \mathrm{~m}$ full scale. To gain more insight in the influence of the relative lateral position, nine additional lateral positions have been tested for a limited amount of test conditions.

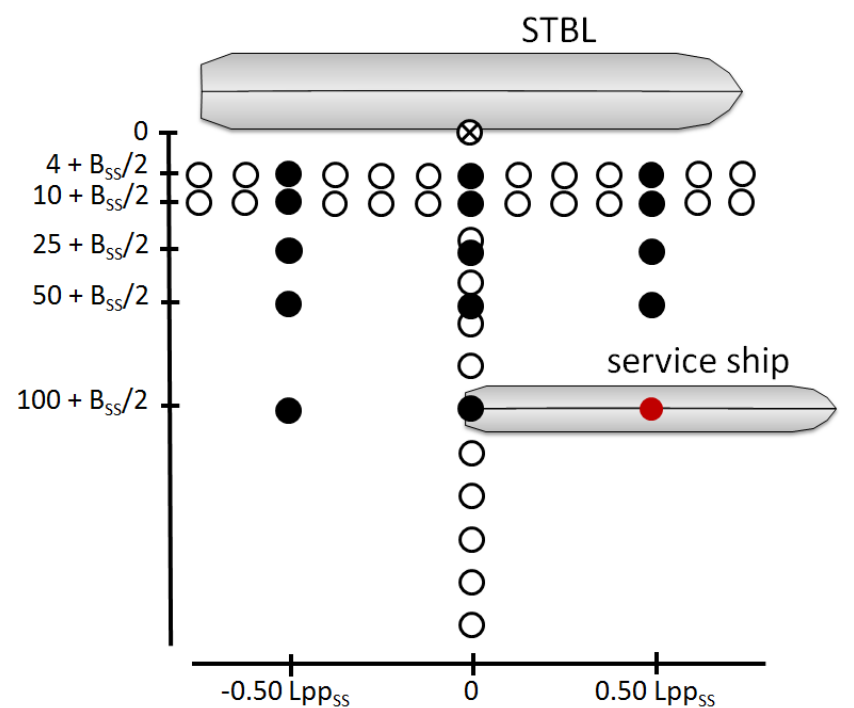

Fig. 2. Relative positions tested systematically (black dots) and not-systematically (white dots)

Three relative longitudinal positions between both vessels have been tested systematically: the midship sections of both vessels at the same relative longitudinal position $\left(x_{c c}=0\right)$, the STBL shifted ahead with a distance equal to half of the length of the service ship $\left(x_{c c}=-\frac{L p p_{S S}}{2}\right)$ and the STBL shifted astern with a distance equal to half of the length of the service $\operatorname{ship}\left(x_{c c}=\frac{L p p_{S S}}{2}\right)$.

$\xi_{S T B L}=\frac{x_{C c}}{L p p_{S T B L}}$

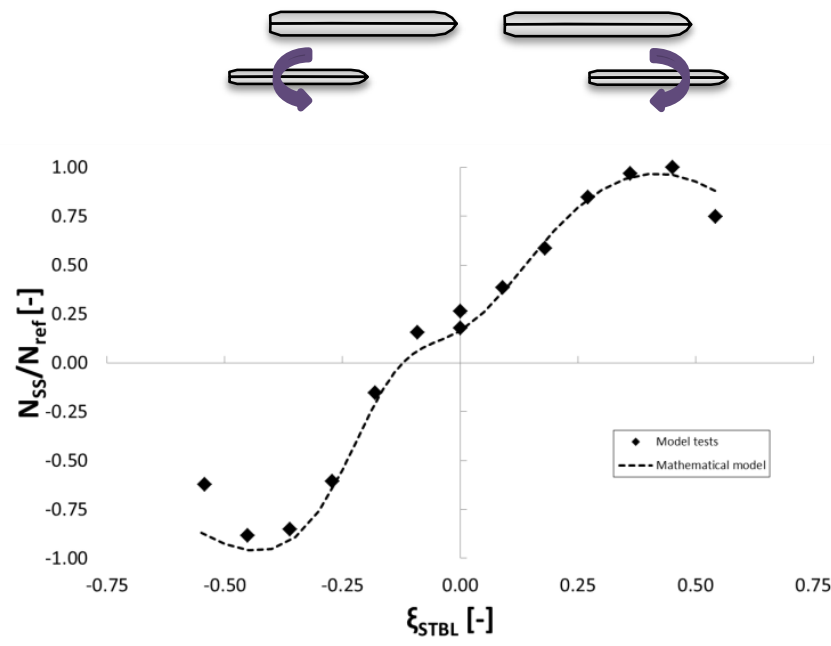

Fig. 3. Measured and modelled values for the yaw moment on the service ship at different relative longitudinal positions between the service ship and the STBL.
Similar as for the relative lateral position, a limited number of tests was carried out with a wider range of relative longitudinal positions (thirteen discrete positions). The systematic combinations of relative lateral and longitudinal positions between both vessels are indicated by black dots in Figure 2, whereas the extra positions which have not been tested systematically are indicated by white dots.

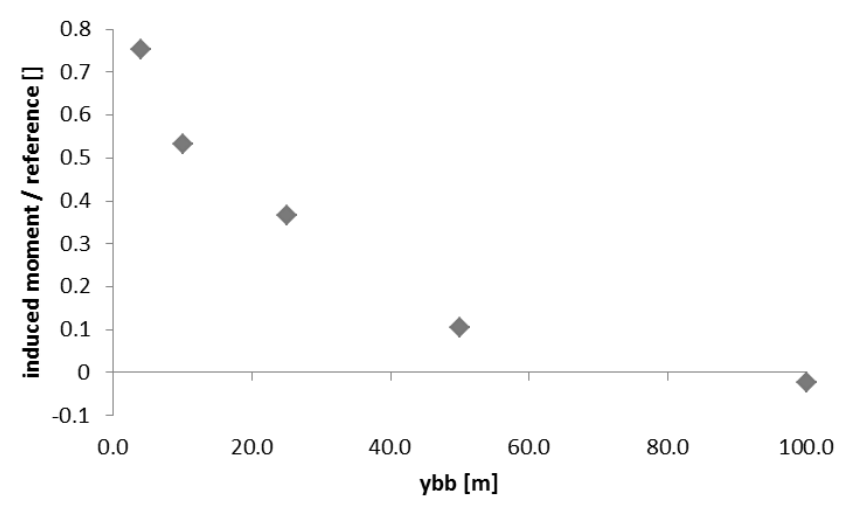

Fig. 4. Yaw moment measured on the service ship model at different relative lateral positions between the service ship and the STBL.

\section{RUDDER ANGLE AND YAW MOMENT}

As shown in Figure 3 the yaw moment is not point symmetric for the relative longitudinal position. Furthermore the most common longitudinal position during lightering is when both midships are at about the same longitudinal position. Therefore the yaw moment for $\xi$-values around zero has to be checked very accurately.

The mathematical model for the yaw moment induced during a lightering manoeuvre to be published in Lataire et al. (2012) is:

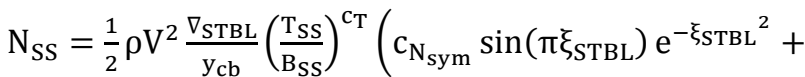

$\left.\mathrm{c}_{\mathrm{N}_{\text {asym }}} \mathrm{e}^{-\left(1.0+\mathrm{c}_{\xi} \xi_{\text {STBL }}\right)^{2}}\right)$

The relative position between both ships (the longitudinal position $\xi$ and the lateral position $\mathrm{y}_{\mathrm{cb}}$ ) will change the magnitude of the hydrodynamic influence of the vessels on each other. The yaw moment induced on the service ship by the STBL when both sail at 4.0 knots for a range of lateral positions is shown in Figure 4. The magnitude of the yaw moment decreases when the lateral distance between both ships increases. The (small) negative yaw moment at the highest $\mathrm{y}_{\mathrm{cb}}$ values tested is ascribed to the bank effects induced by the wall of the towing tank.

In Figure 3 the progress of the yaw moment for a wide range of relative longitudinal positions is shown for the mathematical model and the yaw moment as measured during the model tests.

The yaw moment induced by the close proximity of the STBL will be compensated during a lightering manoeuvre with a rudder angle of the service ship as both vessels try to 
maintain a constant heading and forward speed during the entire manoeuvre. The rudder angle necessary to compensate this yaw moment will be an indication for the feasibility of the lightering manoeuvre.

In Figure 5 the rudder angle is plotted with the yaw moment $\mathrm{N}$ (made dimensionless with a reference value) measured on the ship model during an open water model test in deep water at 6 knots. Between -30 and +30 degrees a linear relation between the rudder angle and the yaw moment is observed:

$\mathrm{N}=\mathrm{N}_{\delta} \delta+\mathrm{N}_{0}$

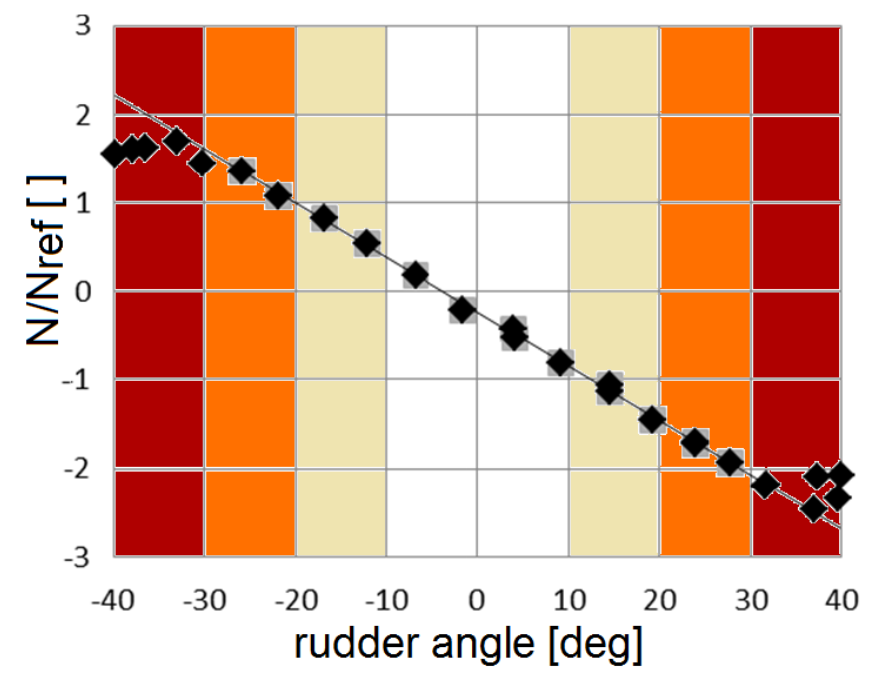

Fig. 5. Yaw moment induced on the service ship by the rudder during an open water test (6 knots sailing speed).

This linear relation has been determined for the other forward speeds ( 2 and 4 knots full scale) both in shallow and deep water and always at a propeller rate according to selfpropulsion. A summary of the results is given in Figure 6 where a quadratic relation between the forward speed and this ratio is found (5). An almost insignificant influence of the water depth on the resulting yaw moment is seen.

$\mathrm{N}_{\delta}^{\prime}=\frac{\mathrm{N}_{\delta}}{\frac{1}{2} \rho V^{2} \nabla}$

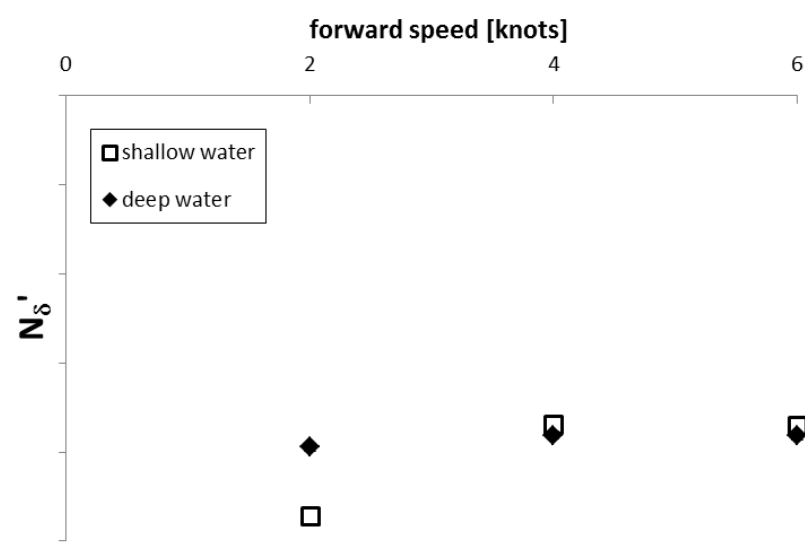

Fig. 6. Rudder coefficient $N_{\delta}^{\prime}$ at different forward speeds and water depths.
Based upon the mathematical model for the yaw moment as proposed in Lataire et al. (2012) and equations (4) and (5), a graph can be plotted for a wide range of relative positions (both longitudinal and lateral) between the service ship and the STBL displaying the rudder angle required to compensate the yaw moment induced during a lightering manoeuvre (Figure 7).

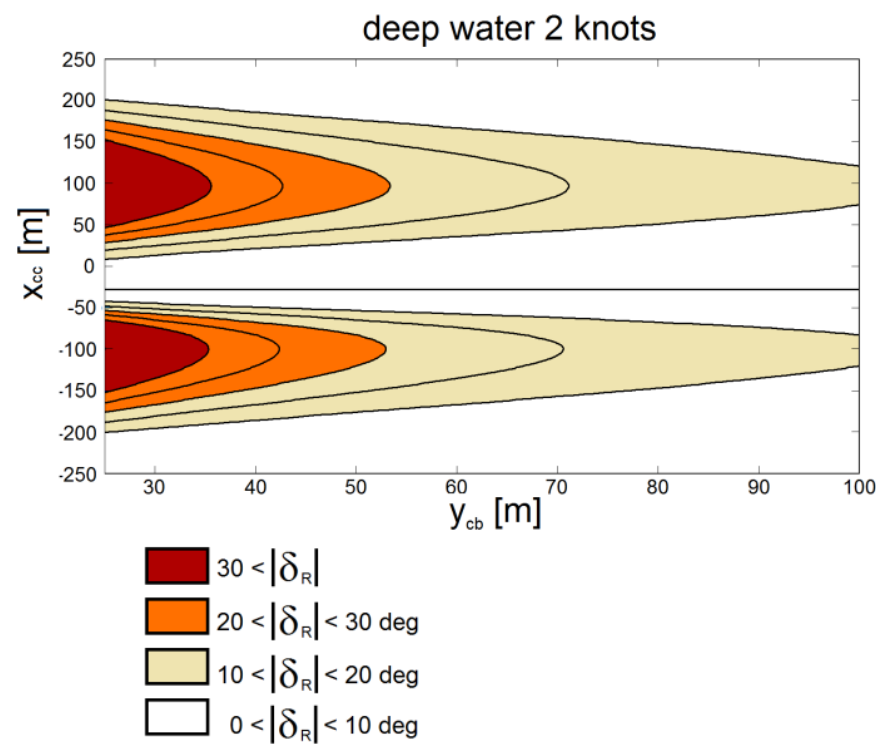

Fig. 7. The rudder angle needed to keep a constant heading during a lightering manoeuvre in deep water at 2 knots

According to Figure 7 four regions can be distinguished:

- Small rudder angles (less than 10 degrees to port or starboard)

- Significant rudder angles (between 10 and 20 degrees to port or starboard)

- Large rudder angles (between 20 and 30 degrees to port or starboard)

- Extremely large rudder angles (more than 30 degrees to port or starboard)

Regions where small or significant rudder angles $(<20$ degrees) are required can be considered to be safe to execute a lightering manoeuvre. In the conditions shown in Figure 7 ( 2 knots in deep water) the lightering manoeuvre should take place (at the smallest lateral distance) at a relative longitudinal position $\mathrm{x}_{\mathrm{cc}}$ between -53 and $30 \mathrm{~m}$. In Figures 8 and 9 similar plots are shown for manoeuvres carried out in deep water at 4 and 6 knots, respectively. At these higher speeds lightering should take place at a relative longitudinal position $\mathrm{x}_{\mathrm{cc}}$ between -57 and $20 \mathrm{~m}$. The difference between the plot at 4 knots and at 6 knots is rather small although the magnitude of the yaw moment during the lightering manoeuvre is significantly higher. Remark that in all tests self-propulsion was presumed, which results in higher propeller rates at higher forward speeds and thus in higher inflow velocities to the rudder profile, which results in an increased lift induced by the rudder. 


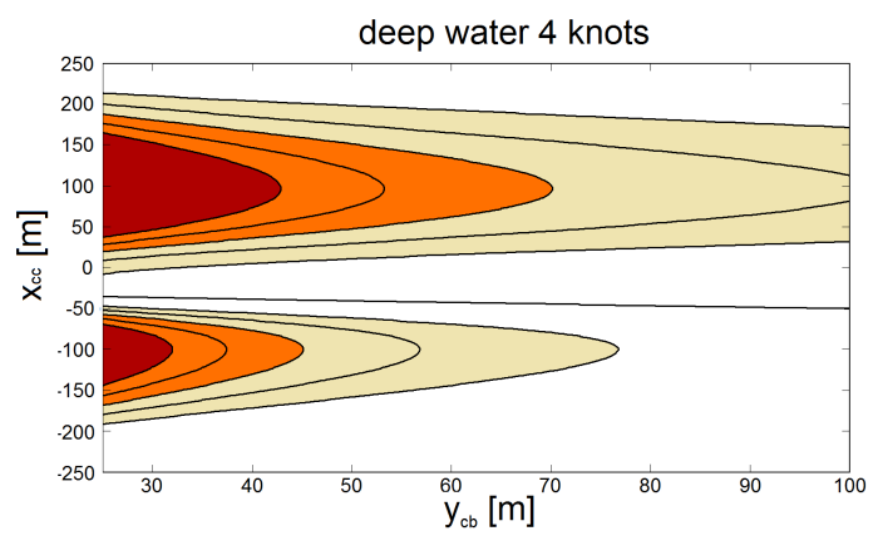

Fig. 8. Rudder angle needed for the service ship to keep a constant heading during a lightering manoeuvre in deep water at 4 knots

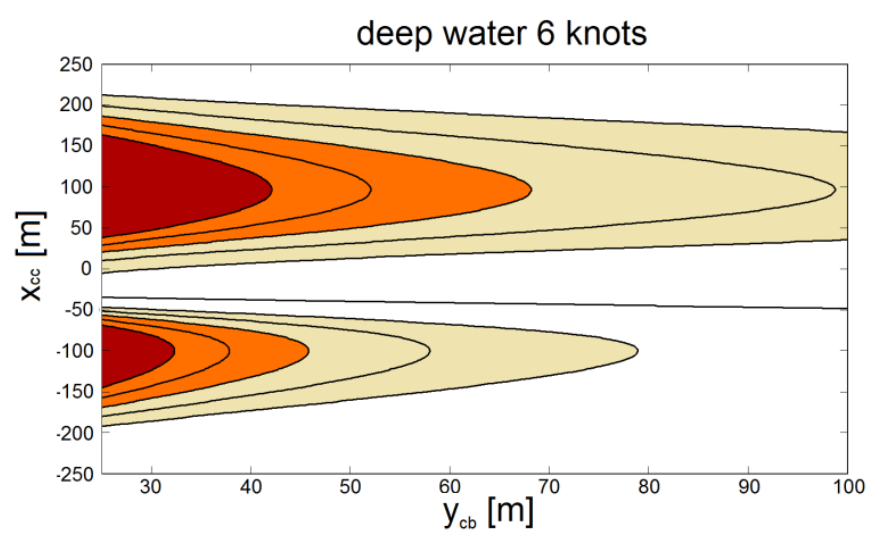

Fig. 9.Rudder angle needed for the service ship to keep a constant heading during a lightering manoeuvre in deep water at 6 knots

In the figures 10 , to 12 the rudder angle needed to compensate the yaw moment during the lightering manoeuvre is plotted when the lightering takes places at a water depth according to an under keel clearance of only $35 \%$ of the ship with the deepest draft, i.e. the Aframax tanker $(\mathrm{T}=15.0 \mathrm{~m})$.

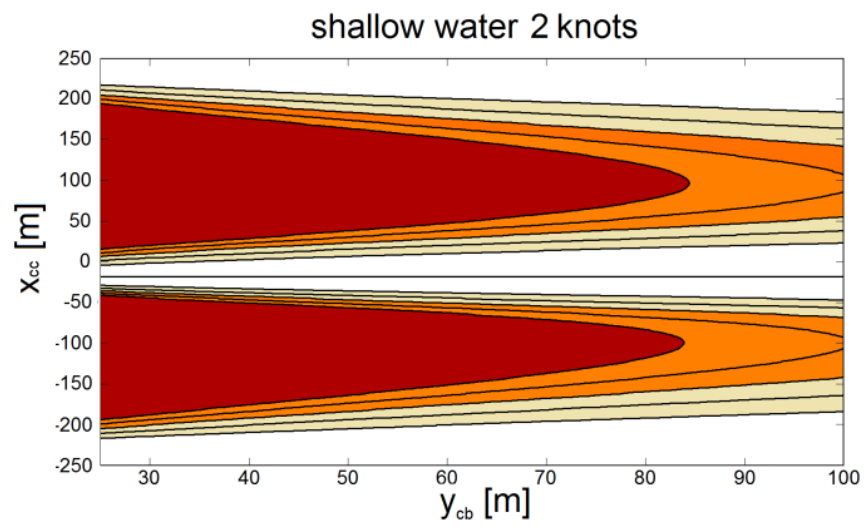

Fig. 10. Rudder angle needed for the service ship to keep a constant heading during a lightering manoeuvre in shallow water at 2 knots

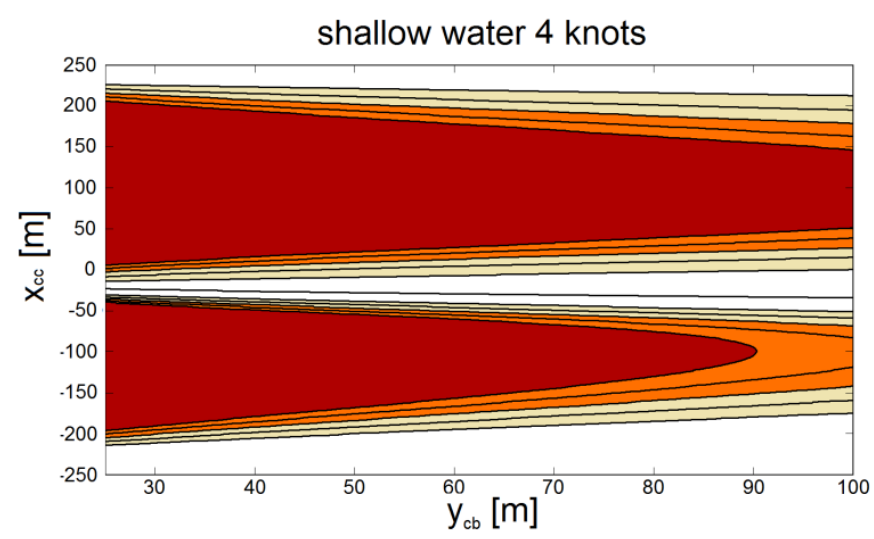

Fig. 11. Rudder angle needed for the service ship to keep a constant heading during a lightering manoeuvre in shallow water at 4 knots

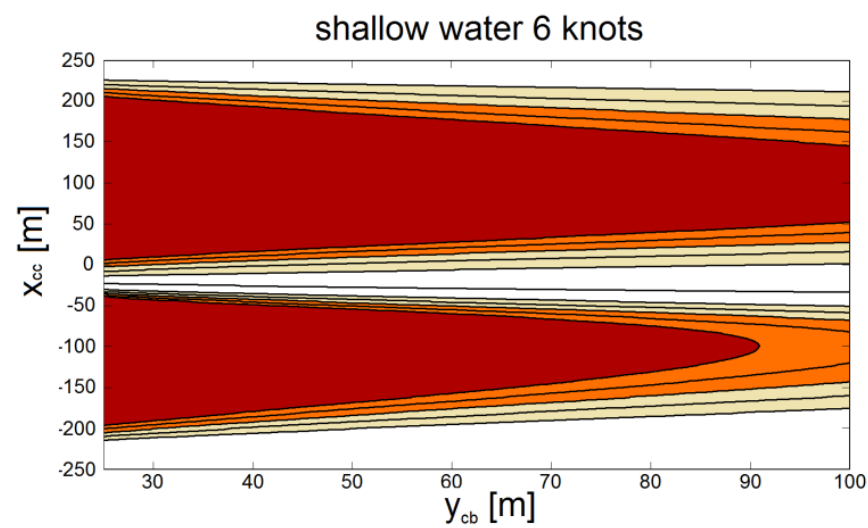

Fig. 12. Rudder angle for the service ship needed to keep a constant heading during a lightering manoeuvre in shallow water at 6 knots

The lightering manoeuvre can be carried out without exceeding 20 degrees of rudder angle whenever the relative longitudinal position $x_{c c}$ is between -35 and $-3 \mathrm{~m}$. This is a rather small range, while many other possible relative longitudinal positions require an extremely large rudder angle. In shallow water this type of lightering manoeuvres can consequently only be carried out in a safe manner if the positions of the manifolds of both tankers allow the lightering to take place in a small acceptable zone. In any case an accurate control of the longitudinal position between both vessels is required during the complete approach and separation procedure.

\section{CONCLUSIONS}

Systematic model tests of a lightering manoeuvre with tankers of the VLCC and Aframax types have been carried out. Based upon this extensive model test program a mathematical model for the yaw moment induced by the proximity of the VLCC on the service ship (Aframax) is presented in Lataire et al. (2012). In open water (deep and shallow) multi-modal model tests are carried out with a varying rudder angle. The results of these tests are used to create a simple model for the yaw moment generated with the rudder of the service ship. 
Both mathematical models are compared and for a wide range of relative positions between the STBL and the service ship, the rudder angle needed to compensate the yaw moment during the lightering manoeuvre is plotted. Based upon these calculations it can be concluded that lightering operations are complex but manageable in deep water, while the execution of such manoeuvres in shallow water requires a very accurate control of the relative position between both vessels.

\section{REFERENCES}

Lataire, E., Vantorre, M., Delefortrie, G., 2009. Captive Model Testing for Ship to Ship Operations. MARSIM '09 Conference Proceedings, pp. M-14-1/10 Panama City, Panama

Lataire, E., Vantorre, M., Delefortrie, G., Candries, M., (2012) Mathematical Modelling of Forces Acting on Ships during Lightering Operations. Ocean Engineering, (under review)

Stern, F.; Agdrup, K. (Ed.) (2008). SIMMAN 2008. Workshop on Verification and Validation of Ship Manoeuvring Simulation Methods, April 14th - 16th 2008: preprints of workshop proceedings: volume 1 . Summary, test cases, methods and papers. Force Technology: Brøndby, Copenhagen, Denmark,

SIMMAN 2008, Workshop on Verification and Validation of Ship Manoeuvring Simulation Methods, Copenhagen, Denmark, April 14th-16th 2008 www.simman2008.dk

Van Kerkhove, G., Vantorre, M., Delefortrie, G. 2009, Advanced Model Testing Techniques for Ship Behaviour in Shallow and Confined Water. Proceedings of AMT 2009 Nantes, France

\section{NOMENCLATURE}

\begin{tabular}{|c|c|c|}
\hline$B$ & {$[\mathrm{~m}]$} & beam of the ship \\
\hline$c_{N s y m}$ & {$[-]$} & coefficient of the mathematical model \\
\hline$c_{\text {Nasym }}$ & {$[-]$} & coefficient of the mathematical model \\
\hline$c_{T}$ & {$[-]$} & coefficient of the mathematical model \\
\hline$c_{\zeta}$ & {$[-]$} & coefficient of the mathematical model \\
\hline$g$ & {$\left[\mathrm{~m} / \mathrm{s}^{2}\right]$} & earth's gravity acceleration \\
\hline$h$ & {$[\mathrm{~m}]$} & water depth \\
\hline$L_{P P}$ & {$[\mathrm{~m}]$} & length between perpendiculars \\
\hline$N$ & {$[\mathrm{Nm}]$} & yaw moment \\
\hline$N_{\delta}$ & {$[-]$} & coefficient of the rudder model \\
\hline$N_{0}$ & {$[-]$} & coefficient of the rudder model \\
\hline$n$ & {$[\mathrm{rpm}]$} & propeller rate \\
\hline$T$ & {$[\mathrm{~m}]$} & ship's draft \\
\hline$U K C$ & {$[-]$} & under keel clearance \\
\hline$V$ & {$[\mathrm{~m} / \mathrm{s}]$} & ship speed \\
\hline$x_{c c}$ & \multicolumn{2}{|c|}{ midship service ship is ahead of STBL) } \\
\hline$y_{b b}$ & {$[\mathrm{~m}]$} & lateral distance between ship sides \\
\hline$y_{c b}$ & \multicolumn{2}{|c|}{ of target ship } \\
\hline$\delta$ & {$\left[{ }^{\circ}\right]$} & rudder angle \\
\hline$\xi$ & $\begin{array}{l}{[-]} \\
\text { sectic }\end{array}$ & $\begin{array}{l}\text { longitudinal distance between the ships' midships } \\
\text { divided by a reference ship length }\end{array}$ \\
\hline$\rho$ & {$\left[\mathrm{kg} / \mathrm{m}^{3}\right.$} & density \\
\hline$\nabla$ & {$\left[\mathrm{m}^{3}\right]$} & displacement volume \\
\hline
\end{tabular}

Subscripts:

$\begin{array}{ll}A & \text { aft } \\ F & \text { fore } \\ R & \text { rudder } \\ S S & \text { service ship } \\ \text { STBL } & \text { ship to be lightered } \\ \text { ref } & \text { reference } \\ 0 & \text { earth bound coordinate system }\end{array}$

